\title{
Wage Differences Matter: An Experiment of Social Comparison and Effort Provision when Wages Increase or Decrease
}

\author{
Jose Rojas-Fallas and J. Forrest Williams * \\ Department of Economics, Portland State University, Portland, OR 97201, USA; josr2@pdx.edu \\ * Correspondence: forrest.williams@pdx.edu
}

Received: 6 October 2020; Accepted: 3 December 2020; Published: 5 December 2020

check for updates

\begin{abstract}
Wage rates, efficiency wages, and gift exchange in a labor market are all crucial aspects in regard to designing contracts to ensure high effort from workers. We extend this literature by discussing the relationship between known differences in wages (social comparison) and workers' effort provision. We conduct an experiment in which subjects perform effort tasks for piece-rates. All subjects are paid the same wage rate in the first half of the experiment, but in the second half are paid different wage rates; the primary variable we study is the information about others' wage rates given to a subset of subjects. We find that subjects' efforts respond strongly to information about others' wages. Such findings have implications for contract structuring for workers.
\end{abstract}

Keywords: social comparison; effort provision; changing wages; lab experiment

\section{Introduction}

A pillar of economics is that individuals respond to incentives; in many conventional models of labor markets, the incentive to which workers respond is their own wage. Of course, over time, this approach has been broadened not just to include wages but all compensation (distance to work, worker flexibility, etc). This framework still operates on the basis that workers choose employment and provide effort based solely on their compensation. However, people may respond to their own compensation and reference points about this level of compensation. An individual's behavior most likely follows the convention of judging her wage against her past wages in some manner [1]. Consider an entry-level employee who expects to be paid minimum wage but instead gets paid one dollar more than this amount. She might consider such a wage in a positive light if her reference point is the minimum wage rate and increase productivity significantly [2]. Consider how she might react if the minimum wage suddenly increases to her current wage. In traditional economic theory, her compensation is unchanged so that one would predict no change in behavior. Nevertheless, if her reference point has moved to the new minimum wage, she is now not being paid a premium over her reference point, and her behavior may change; one might expect either a decrease in the extensive margin (less work) or intensive margin (lower productivity when working) or both. This setting rests in the gift exchange problem with workers and employers. Fehr et al. [3] summarize this strand of literature. Of course, the value to which she compares her wage might not be the minimum wage, but the wages of her colleagues or others who do similar tasks.

Questions about effort provision and fairness are not new. There is a strand of worker effort and fairness research that extends back to the 1960s in Sociology pioneered in many ways by J. Stacy Adams; a review of his contributions is summarized in Miner [4]. The key insights from his theoretical and experimental work are that individuals care about perceived (in)equity, impacting effort in meaningful ways. For example, a small underpay inequity leads to a much more significant job performance change than a small overpay inequity [5]. 
This paper presents a real-effort task experiment in which subjects who are given information about others' wages behave very differently than those who do not know this information. This situation deviates from the standard gift-exchange problem between workers and employers and allows for social comparison and fairness to influence job effort. If worker A knows that worker B gets higher compensation for the same job, Worker A might see Worker B's wage as the reference point and believe she is underpaid. This effort would likely be more substantial if they were friends or a member of the worker's social network [6]. This same situation could happen in reverse; those getting more than others for doing the same job (and knowing this fact) may increase their effort. Prior knowledge of a change in wages would also mitigate the effect of the change on reactionary effort [7].

Our results indicate the workers do care about others' wages in reference to their own. We find evidence that subjects change the effort provided in effort tasks when they discover that other workers are being paid a different wage rate than they are. Perhaps most interestingly, the level of the wage rate is less impactful on performance than the relative wage of others. Subjects who have a wage cut but discover others to a larger wage cut increase their effort.

We organize the reaming paper in the following manner: Section 2 details the related literature. Section 3 introduces the experimental design. Then we discuss the results of the experiment in Section 4. The paper concludes with Section 5, where we discuss our findings.

\section{Literature Review}

We use a controlled lab experiment to isolate the effect of information about others' wages on productivity/effort provision; isolating this effect is nearly impossible beyond the laboratory setting. When a subset of subjects receives information about others' wage rates, they can compare those rates to their own wage. This social comparison can impact effort. Charness and Kuhn [8] show that workers are responsive to their own wages more than they are to another worker's wages. In a field experiment, Hennig-Schmidt et al. [9] show that worker effort is unaffected by an increase in her own wages or comparisons to peers' wages. Similarly, Bartling and Von Siemens [10] look at team production and find that wage inequality has no significant impact on production. This result of wage inequality not having a substantial impact on production is not universal. In Sseruyange and Bulte [11], the subjects did a simple task for wages; treatments allow workers to communicate and thus have social comparisons of wages. They find that effort is not driven by a worker's wages but is heavily influenced by this comparison in an unpaid follow-up task. Our work's key difference is that we study the impact of wages changing (increasing and decreasing) to see if this effect of social comparison is similarly impactful when workers are given raises or face cuts due to exogenous shocks. The data show that knowledge of others' wages is significantly impactful, both when all workers' wages increase or decrease-the direction of wage movement is not nearly as impactful to effort relative to the impact of social comparison of wage rates.

We test this circumstance where knowledge about the range of wages affects workers' performance in a stylized setting. Though social comparisons of wage rates likely are happening all the time, we believe observing such occurrences with precision in the field is exceedingly challenging. Thus, we rely on a laboratory experiment to test this aspect of behavior; we conduct a real-effort task experiment that involves giving a subset of subjects information about other workers' wages. In this way, we can compare the effort given by those with this knowledge to those without it.

Effort provision and performance can originate from many different sources. These sources can be either endogenous or exogenous. Reference-dependence is an example of effort being influenced endogenously. An individual sets their subjective reference point based on many possible factors such as recency, preferences, perceived fairness, etc. [12-14]. The concept of reference-dependence is one of the critical insights of Prospect Theory [15,16]. Gilchrist et al. [17] explore reference points impact productivity using an experiment where subjects could receive a surprise gift on top of their wages in a gift-exchange experiment. They find an unexpected gift leads to higher productivity compared to the 
equivalent wage that a worker expected. Such findings suggest that it is not the level but the framing of compensation or comparison to another wage that matters to worker effort.

Fehr et al. [3], in a meta-analysis of labor markets, provide the understanding that fairness has only weak effects in one-shot interactions. They attribute the low power of fairness to the inter-individual differences among experimental participants, where selfish actors outweigh the fair-minded individuals. They conclude that experimental evidence suggests that reference-dependence social preferences play an essential role in a person's motivation and, by extension, effort provision. Support for this finding is shown in a field experiment [18] in which subjects who experienced a unilateral wage decrease have lower performances than groups of subjects that all had their wages cut in the other treatment groups.

Additionally, Abeler et al. [19] summarize recent experimental work on equity and efficiency in multi-worker settings. Relatedly, Pfeffer and Lanton [20] show that wage inequalities can impact productivity and job satisfaction among university faculty members and that information about others inputs (qualifications, past experience, etc.) and rewards (wages, marginal benefits, etc.) is the foundation for feelings of inequality.

Our research provides support for fairness perception affecting worker productivity, as it is the only measurable difference between treatments. Similarly, it is important to ask if fairness impacts behavior equally based on if the wage change is positive or negative; positive changes seem to have no statistically significant effects over the perceived status quo. Negative changes do impact productivity [21].

Perceived fairness impacts the productivity of workers; fairness is often a function of reference points. Thus, it is essential to understand how perceived fairness can affect effort provision when wages change. We acknowledge that fairness as a concept evolves endogenously, and how and when individuals update their reference point is not fully understood. Though a worker's reference point is primarily influenced by her own past wages [22], it is not necessarily the only influence. There could be a cultural norm that is exogenous to the worker's past wages, which is subject to shift with time [23]. Due to shifting cultural norms, understanding the potential effects of fairness has policymaking and labor market implications. Specifically, fairness can have effects on productivity through reciprocity [24]. A worker may adjust their behavior (effort provided) if they believe that "established norms" have been violated; the direction depends on the type of norm violation. A worker who provides more effort than is necessary will reduce their effort [25].

The decision to perform or increase effort provision when facing higher prospects, relative to expectations, has been proven to hold over different settings [26-29]. Individuals act in a loss-averse manner when they are in a context of unexpected outcomes [11]; they trend towards their established status quo, which is easier to rationalize and requires a little cognitive cost to establish.

Our research contributes to the field of reference-dependence by empirically measuring and comparing individuals' performance when they can compare their wages to other workers.

\section{Experimental Design}

We conducted experimental sessions at a regional public university campus over two weeks using pen and paper. We informed subjects that their participation was voluntary and had no bearing on their grades in courses or standing in the university. Further, we instructed subjects they would be paid in cash. The experiment involved a real-effort task with two parts; each part was timed for three minutes in duration, totaling six minutes total for all effort tasks performed. During all the experimental sessions, the subjects had opportunities to ask the experimenter any clarifying questions. During each of the two effort periods, subjects were informed via the sound of a bell that thirty seconds remained to complete as many tasks as they could. The individual task itself was identifying how many times a given number appeared in a $4 \times 4$ grid. The grid had randomly generated numbers and 
was limited to digits ranging from 3 to 9 , inclusive. There were nine grids per page and a total of twelve pages yielding 108 grids in each part. ${ }^{1}$

To obtain credit and earn money for her effort, the subject had to correctly count and write the exact amount of times their specified number appeared in the space provided below the grid. See Figure 1 below for an example grid; here, the task involved finding the number 6 and correctly identifying two are present. An answer was correct only if the written number was an accurate count; any other answer was counted as inaccurate and did not count towards the subject's earnings.

\begin{tabular}{|l|l|l|l|}
\hline 4 & 3 & 6 & 7 \\
\hline 9 & 9 & 3 & 5 \\
\hline 7 & 5 & 5 & 3 \\
\hline 5 & 4 & 4 & 6 \\
\hline
\end{tabular}

Figure 1. Example of a $4 \times 4$ grid of numbers the subjects would see.

To begin the experiment, the researcher read the instructions to the subjects after they had signed the informed consent form and decided to participate. The subjects knew that their payment would be dependent on their performance during the session. Additionally, subjects received a participation payment of $\$ 1.50$. This amount might appear to be a low rate of compensation for the participants. However, the entirety of the session lasted no more than twenty minutes. The subjects, on average, would earn above $\$ 15$ per hour. In this manner, the subjects were compensated adequately for the opportunity cost of their time. The average payment for participants was $\$ 7.35$ for the session, which comes to an hourly pay of $\$ 22.05$. The minimum payment was $\$ 3.12$, and the maximum payment was $\$ 13.74$ per session, which amounts to $\$ 9.36$ and $\$ 41.22$ hourly, respectively.

Before beginning the first set of effort tasks, the subjects were verbally informed that they would receive "slightly more (less)" per correctly answered grid during the second effort task. The positive (negative) group is where wage rates increase (decrease) in the second task. The positive treatment group was told "slightly more" and the negative treatment group was told "slightly less." We use both an increasing and decreasing wage as there might be differential effects of social comparison of wage rates if subjects were earning more or less in real terms. The subjects knew that the first-round wage rate was $\$ 0.06$ per correctly completed task.

Once they finished the first task, the booklets of their effort tasks were collected, and the experimenter distributed a demographic survey. The subjects then completed a demographic survey between the effort tasks to give subjects a break from providing continuous effort and assuage any fatigue concerns. The experimenter reminded subjects that their wage rates were going up (down) in the next effort task during this period.

When beginning the second effort task portion of the experiment, the experimenter told subjects to carefully read the instructions as they may be searching for a different number during this effort task. The instructions in the second part also had information regarding the wage shock in bold text. The treatments differ in what the subject was paid in the second task, the location of the new wage relative to her first task wage rate, and how that information was given to her.

1 Full tasks, instructions, and data used in Section 4 are included in the Supplementary Materials. 
For example, in the wage increasing treatments, one treatment has instructions that inform the subject that she could have earned up to $\$ 0.08$ but will be receiving $\$ 0.07$ per correct grid. ${ }^{2}$ The subjects in another positive (wage-increasing) treatment would have only read that they will be receiving $\$ 0.07$ per correct grid. This difference in how the seven-cent wage is presented should create a shock-even though both workers know they earn $\$ 0.07$ in the second task, which was higher than the first task, some have the extra information that a higher wage was possible and that someone in their cohort will be earning that amount because instruction booklets/effort tasks were randomly assigned. If we observe a difference in behavior between two treatments whose workers are paid the same rate, it is likely due to the information (or lack thereof) regarding others' wages.

Table 1 illustrates the treatments discussed in this experiment. ${ }^{3}$ The treatments were randomized both between and within sessions. The Five-I and Five-NI treatments were in different sessions than the Seven-NI and Seven-I treatments. Subjects were instructed only about the direction of the wage change between the first and second tasks through the "slightly more (less)" verbal instruction during the first round and demographic survey. The magnitude of change of wages in the second effort task was not disclosed until that task began. In this way, the experiment informs us if a social comparison of wages responds similarly in real wage gain and loss domains. The treatments vary only in the second tasks' wage rate and information about others' wages for these tasks. The treatments are written in the format: Second effort task wages-(No) Information.

Table 1. Treatments.

\begin{tabular}{cc}
\hline Treatment Name & 2nd Effort Task Payment Information \\
\hline Five-I & Could have earned $\$ 0.04$, Will be earning $\$ 0.05$ \\
\hline Five-NI & Will be earning $\$ 0.05$ \\
\hline Seven-NI & Will be earning $\$ 0.07$ \\
\hline Seven-I & Could have earned $\$ 0.08$, Will be earning $\$ 0.07$ \\
\hline The I and NI in treatment names indicate Information and No Information, respectively
\end{tabular}

We presume that individuals have a utility function in the spirit of [12], as shown in Equation (1). This additively separable function gives individuals direct returns on their effort provision from wages, $v(w)$, includes costs of effort provision, $d(e)$, and a morale function, $M(e ; w, r)$ which exhibits loss aversion (Kahneman and Tversky 79 and 91) and includes a reference wage.

$$
u(e ; w, r)=v(w)-d(e)+M(e ; w, r),
$$

Our paper's main takeaway from this modeling is that when wages are above a reference point, a worker increases her effort, ceteris paribus. This increase in effort is due to her viewing the wage premium (wage-reference wage) as a gift. Conversely, she would decrease effort if the wage were below her reference point. In this paper, the introduction of others' wages can serve as a reference point for a worker via social comparison. In this manner, we formulate the following hypotheses for our experiment:

Hypothesis 1. Effort in Five-I will be greater than effort in Five-NI.

2 The exact wording in the relevant portion of the experimental instructions for those subjects who knew of other possible wages is, "Though the highest (lowest) you could earn was $\$ 0.08$ (\$0.04) per grid, you will be paid $\$ 0.07$ (\$0.05) per grid."

3 To avoid issues with deception, a small number of subjects were paid either $\$ 0.08$ or $\$ 0.04$ per task in the second effort portion, depending on the sessions being run. Thus, it was possible for some subjects to receive the extreme payoffs which were used to engage the social-comparison effort provision. As there are only a small number of subjects in these "treatments" we exclude them from any analysis in this paper as there is no statistical power to say anything about their effort. 
In both treatments, subjects are paid the same wage rate in real terms, so $v(w)$ is identical and perform identical tasks, so $d(e)$ is likewise the same. However, those in the Five-I treatment know that some other workers are being paid less than them. If via social comparison a worker sets the reference wage as the wage of those making less than her, she may perceive her current wage as a gift and provide higher effort via the morale function $M(e ; w, r)$ than those in the Five-NI treatment who do not have this knowledge.

Hypothesis 2. Effort in Seven-NI will be greater than effort in Seven-I.

As in Hypothesis 1, subjects in these treatments are all paid the same real wage, but those in the Seven-I treatment know that others receive a higher wage. This information leads Seven-I subjects to view their wages as unfair through social comparison; due to this perception of unfair wage rates, Seven-I workers lower effort relative to those in Seven-NI who cannot make this comparison.

Hypothesis 3. Effort in Seven-NI will be greater than effort in Five-NI.

In each of these treatments, subjects are unaware of others' wage rates. We expect those who are getting a wage (Seven-NI) to give more effort than those being paid a lower wage rate (Five-NI). This behavior is based on $v(w)$ being higher in Equation (1) for those in the Seven-NI treatment than those in the Five-NI treatment. In both treatments with no information about others' wages, there is no social comparison, and the cost of effort provision is identical. ${ }^{4}$

\section{Results}

We begin our statistical analysis of the data by investigating differences in the level of successful effort given in the first task measured by the number of completed tasks, where all wages are the same for all subjects. ${ }^{5}$ A Kruskal-Wallis test (a non-parametric test to measure if samples are from the same distribution) on this task across all treatments reveals no differences in successful effort provision $(p=0.691)$. Further, we compare the first-round effort in the treatments where wages will fall (Five-I and Five-NI) against those where they rise (Seven-I and Seven-NI) using the non-parametric Wilcoxon Rank Sum test $(p=0.689)$. Thus, the knowledge that wages will increase or decrease in the second round of effort tasks does not influence current effort. This outcome can be seen visually in Figure 2. This figure is a box-whisker graph where the bottom end of the box represents the 25th percentile, the top end of the box is the 75th percentile, and the bar inside the box itself is the median value. Whiskers extend to the upper (lower) adjacent values, which we define to be the largest (smallest) observation that is less (greater) than the upper (lower) inner fence calculated as the third (first) quartile plus (minus) 1.5 times the interquartile range. Points beyond these values are outliers. We display these outliers, when they exist, as dots beyond the upper (lower) adjacent values. All future boxplot graphs use the same convention.

4 We acknowledge that there may be another effect that influences effort that is impossible to disentangle in the direction of wage change. Though we suspect the direction of the effects would be similar (e.g., wages increasing impacts behavior in the same direction that having a higher wage would), we cannot determine the magnitude of these effects independently with our data.

5 A breakdown of the demographics of the 130 total subjects by treatment is shown in Table A1 of the Appendix A. Demographic data was collected through self-reporting by participants. Some participants did not answer questions about their race or gender. 


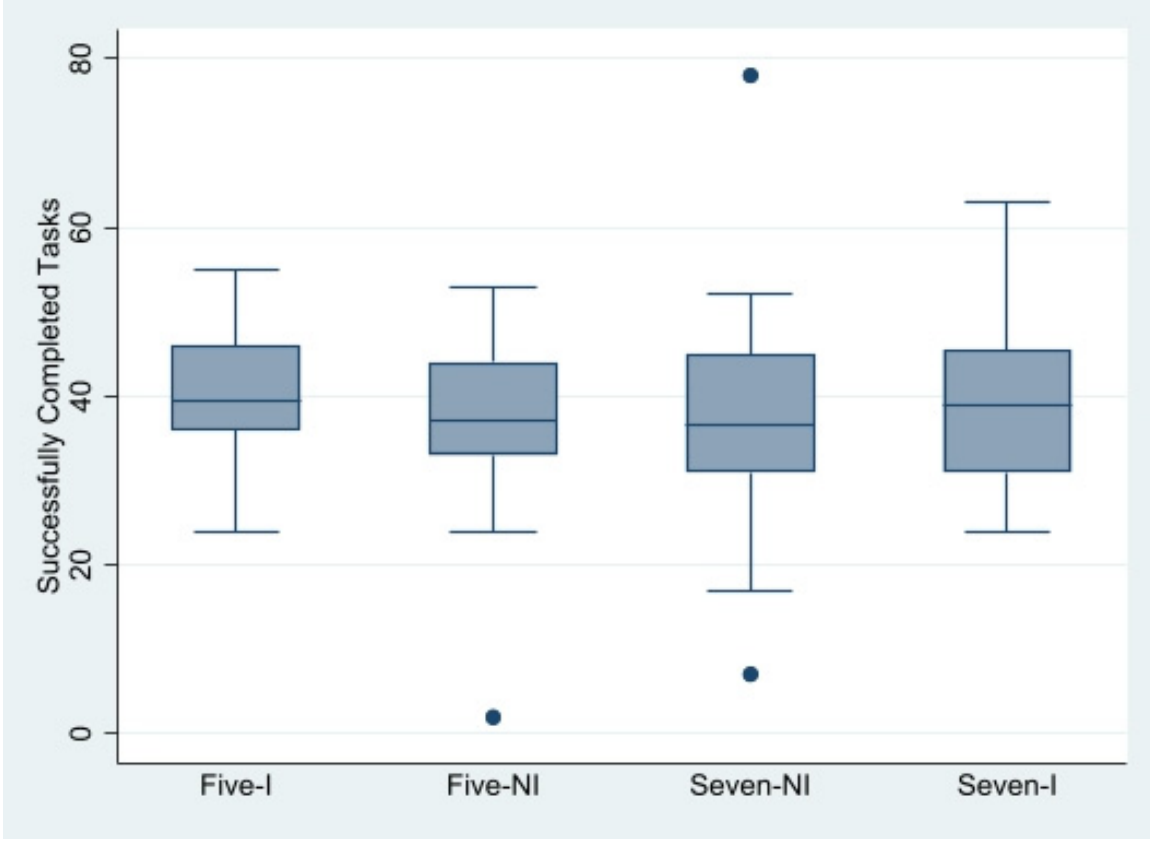

Figure 2. A box-whisker plot of subject effort during Task 1 by Treatment.

Regarding the second effort task, there are differences in the number of completed effort tasks show with a Kruskal-Wallis test $(p<0.001){ }^{6}$ Figure 3 visualizes the medians of the outcomes. The effort in Task 2 in treatments Five-I and Seven-NI are both statistically significantly different than the effort provided in Task 1.



Figure 3. A box and whisker plot of subject effort in both Task 1 and Task 2 by Treatment.

6 We note that in the Five-I and the Seven-NI treatments, two subjects (one in each treatment) were able to complete all the possible tasks (108). The findings are unchanged even if we drop these outliers. 
We next investigate Hypothesis 1 . In the Five-I treatment, subjects receive information that some other subjects are earning $\$ 0.04$ per task while earning $\$ 0.05$; this information of others' wage rates was not given to those in the Five-NI treatment. Recall Hypothesis 1 is that workers in Five-I will give higher effort than Five-NI in the second effort task. We use a Wilcoxon Rank Sum test to test this hypothesis. This non-parametric test indicates that the two distributions are not from the same sample $(p<0.001)$. Given the observed differences in behavior between Five-I and Five-NI, it appears subjects respond strongly to this information that allows them to compare their wages to another subject's - even when they are not sure which subject(s) or how many others exist at this wage that is not their own. This information leads them to be in what we call "relative positive domain"; even though they are being paid less in absolute terms, it is relatively more than it could have been, and thus, they work harder than if they were just told they would be earning $\$ 0.05$ as the realization of lower wages in the second task (Five-NI treatment).

Similarly, we test Hypothesis 2, which argues that successful effort will be higher in the Seven-NI treatment than in Seven-I treatment. As before, we use the Wilcoxon Rank Sum test and find that the two distributions of effort are not the same in the second effort task $(p<0.001)$. In the Seven-NI treatment, the subjects have no information about others' wages and only know their rate of $\$ 0.07$. Conversely, those in the Seven-I treatment know that some subjects earn a wage of $\$ 0.08$, which is higher than the wage of $\$ 0.07$ they receive. The data show that when individuals are only aware of their wage increase, they will outperform those who get the same increase and aware that others received an even larger increase. We call this the relative loss domain, as the real wages have increased, but subjects may perceive a loss when comparing to the wages of others.

Next, we discuss Hypothesis 3, which concerns the relationship between the effort in Seven-NI and Five-NI. Neither of these treatments has information about others' wage rates. If higher wages encourage increased effort, the Seven-NI effort in the second task will be higher than Five-NI. We confirm this using the non-parametric Wilcoxon Rank Sum test $(p<0.001)$. Thus, when there is no knowledge of others' wage rates, wage increases lead to increased worker productivity.

After all non-parametric investigations, we run a regression analysis on the successful effort in Task 2 as a way to control for potential non-treatment effect influences on our subject's behavior. These regressions are seen below in Table 2. For all regressions in Table 2, each column is an ordinary-least squares model where the dependent variable is the number of completed tasks during the second task, and all even-numbered columns are the same regression as the previous odd column with demographic controls added. Columns 1 and 2 use data only in the treatments where the wages increased (Seven-I and Seven-NI). Similarly, columns 3 and 4 are only those where the wage rate falls (Five-I and Five-NI). Lastly, columns 5 and 6 include all data. The level of completed tasks in the first effort task (Task 1$)$ is in all the regressions, and it is always statistically significant $(p<0.001){ }^{7}$

7 Using a Wald test, we find no statistical difference in the coefficients on Task 1 when comparing (1) and (3) ( $p=0.293)$ and (2) and (4) $(p=0.993)$. 
Table 2. Ordinary Least Squares Regression on Effort in the Second Task.

\begin{tabular}{|c|c|c|c|c|c|c|}
\hline Task 2 & (1) & (2) & (3) & (4) & (5) & (6) \\
\hline Task 1 & $\begin{array}{c}1.255^{* * *} \\
(0.182)\end{array}$ & $\begin{array}{c}1.307^{* * *} \\
(0.174)\end{array}$ & $\begin{array}{c}0.996^{* * *} \\
(0.200)\end{array}$ & $\begin{array}{c}0.908^{* * *} \\
(0.180)\end{array}$ & $\begin{array}{c}1.152 * * * \\
(9.46)\end{array}$ & $\begin{array}{c}1.172 * * * \\
(9.07)\end{array}$ \\
\hline Five-I & - & - & omitted & omitted & omitted & omitted \\
\hline Five-NI & - & - & $\begin{array}{c}-26.81^{* * *} \\
(2.884)\end{array}$ & $\begin{array}{c}-26.71 * * * \\
(3.040)\end{array}$ & $\begin{array}{c}-26.37^{* * * *} \\
(-9.24)\end{array}$ & $\begin{array}{c}-26.49 * * * \\
(-7.47)\end{array}$ \\
\hline Seven-NI & omitted & omitted & - & - & $\begin{array}{l}-2.786 \\
(-0.63)\end{array}$ & $\begin{array}{l}-3.182 \\
(-0.87)\end{array}$ \\
\hline Seven-I & $\begin{array}{c}-25.94^{* * *} \\
(4.008)\end{array}$ & $\begin{array}{c}-27.24^{* * *} \\
(3.640)\end{array}$ & - & - & $\begin{array}{c}-28.66^{* * *} \\
(-10.14)\end{array}$ & $\begin{array}{c}-29.82 \text { *** } \\
(-7.54)\end{array}$ \\
\hline STEM $^{+}$ & & $\begin{array}{c}3.471 \\
(4.163)\end{array}$ & & $\begin{array}{l}-2.744 \\
(5.095)\end{array}$ & & $\begin{array}{l}3.217 \\
(0.88)\end{array}$ \\
\hline Other Major & & $\begin{array}{c}0.629 \\
(6.347)\end{array}$ & & $\begin{array}{c}0.105 \\
(3.346)\end{array}$ & & $\begin{array}{l}0.511 \\
(0.16)\end{array}$ \\
\hline Female & & $\begin{array}{c}3.068 \\
(5.832)\end{array}$ & & $\begin{array}{c}-5.384 * \\
(2.987)\end{array}$ & & $\begin{array}{l}-1.392 \\
(-0.52)\end{array}$ \\
\hline Caucasian & & $\begin{array}{c}2.665 \\
(4.329)\end{array}$ & & $\begin{array}{c}4.001 \\
(3.073)\end{array}$ & & $\begin{array}{l}2.255 \\
(0.88)\end{array}$ \\
\hline Risk Taker & & $\begin{array}{l}-1.527 \\
(4.693)\end{array}$ & & $\begin{array}{c}4.494 \\
(2.954)\end{array}$ & & $\begin{array}{l}2.266 \\
(0.89)\end{array}$ \\
\hline Constant & $\begin{array}{c}22.18^{* * *} \\
(7.461)\end{array}$ & $\begin{array}{l}16.86 * \\
(9.579)\end{array}$ & $\begin{array}{c}35.14^{* * *} \\
(8.629)\end{array}$ & $\begin{array}{c}37.22^{* * *} \\
(7.612)\end{array}$ & $\begin{array}{c}28.88^{* * *} \\
(5.10)\end{array}$ & $\begin{array}{c}26.44^{* * *} \\
(4.22)\end{array}$ \\
\hline$N$ & 62 & 60 & 68 & 67 & 130 & 127 \\
\hline
\end{tabular}

${ }^{\dagger}$ Science, Technology, Engineering, and Mathematics Majors. Standard errors in parentheses. ${ }^{*} p<0.05,{ }^{* *} p<0.01$, **** $p<0.001$.

We now turn to the treatment effects. First, we consider columns 1 and 2, focusing on the treatments where wages have increased in Task 2 . The coefficient on Seven-I is negative and statistically significant $(p<0.001)$. The results indicate that those in the Seven-I treatment complete approximately twenty-six fewer tasks than those in the Seven-NI treatment. To put this number in perspective, the average number of completed tasks for Seven-NI during the second task was 70.1 tasks, so the roughly twenty-six fewer tasks are approximately $37 \%$ of the average of the Seven-NI effort. Similar to our analysis of columns 1 and 2, we look at the treatment effects in the case where wages have fallen for the second effort task (columns 3 and 4). The coefficient variable on Five-NI is always negative and statistically significant $(p<0.001)$. This coefficient's value is approximately negative twenty-seven, indicating that subjects in this treatment complete roughly twenty-seven fewer tasks during the second period. The average number of tasks completed in Five-I is 74.9, so the treatment effect is effectively a $36 \%$ decrease in subjects' production.

These impacts due to social comparison seem very large, especially given such minor differences in the piece rate. However, subjects could do many of these per minute, which can sum up to a sizeable hourly wage impact; if a subject completes forty tasks per three minutes, on average, a one-cent difference per task becomes an hourly wage difference of $\$ 8.00$ per hour.

We include demographic information in the even-numbered columns. These additional measures do not economically or statistically significantly influence the coefficients on Task 1 or treatment variable coefficients. The parametric regression results confirm all the non-parametric findings. Even when controlling for demographic factors such as major (STEM, and other non-economics or business majors where Econ/Business Major is the excluded category), gender, race, or self-described risk-taking, we find robust treatment effects.

Both regression and non-regression analysis indicate the same behavior; subjects who know that workers were randomly selected to earn different wages than themselves alter their performance compared to those workers who did not know other workers had a different wage rate. We see this 
outcome fully as the Five-NI treatment having different magnitudes in performance and earnings than Five-I. Likewise, the Seven-NI treatment has significant differences in performance than treatment Seven-I. We infer that added information of others' wage rates can directly impact the effort from these data. The direction of this impact is also dependent on the worker's relative wages to others; if a worker makes less than a colleague, she decreases her effort. Conversely, when a subject knows her wage rate is higher than her colleague's, her effort increases. The result is true even when the subject's actual wage rates have decreased.

\section{Conclusions and Discussion}

This article presents experimental evidence on how workers respond to the knowledge of others' wages that change more than the worker's wage. The knowledge about others' wages creates a social comparison that matters, and influences effort more proudly than real wage changes seem to do. We find that subjects who get paid a specific real wage rate and are also given additional information about others' wage rates behave systematically differently than subjects without the additional information with the same real wage rate. This result holds for both increased piece-rates and decreased piece-rates relative to the initial wage rate. The direction of the change in behavior (increasing or decreasing effort) is a function of a worker's wages relative to others' wages for the same task.

When individuals know they could have earned less than they were being compensated, they gave a better performance than those who did not know this information about others' wages. In fact, as some subjects had smaller real wages in the second task in our experiment, they increased effort significantly due to this information. In the situations where a worker's wage rate increased, workers who saw they were earning less than other workers performed worse than those who were only made aware of how much more they will be earning. The behavior is consistent with the expected behavior for loss-averse individuals. They favored or performed better in treatments in which they could have experienced more losses or were not made aware they could have earned more (which one might still consider a loss in a relative sense). Those who saw minor losses relative to more considerable potential losses internalized the wage cut as a gain, even though it was monetarily a loss. Those who saw minor gains with the chance of potentially larger gains gave less effort; the losses they felt compared to the reference point dominated the actual wage gain occurring. These results are consistent with fairness concerns.

Our findings are significant in the realm of labor markets as employers may affect workers' performance if they do not adequately understand incentive structures; workers with similar tasks who receive different wages may have larger differences in performance/effort than can be explained by the level of wages alone. It is unclear to what extent this behavior would translate into other effort-giving domains such as students at school. If parents or teachers reward different students differently for the same grades, students might respond not to their own direct incentive but also to those of their classmates.

Supplementary Materials: The following are available online at http://www.mdpi.com/2073-4336/11/4/59/s1 De-identified data and codebook; Experimental instructions.

Author Contributions: Conceptualization, J.R.-F. and J.F.W.; methodology, J.R.-F. and J.F.W.; software, J.R.-F.; validation, J.R.-F. and J.F.W.; formal analysis, J.R.-F. and J.F.W.; investigation, J.R.-F. and J.F.W.; resources, J.R.-F. and J.F.W.; data curation, J.R.-F.; writing-original draft preparation J.R.-F. and J.F.W.; writing-review and editing, J.R.-F. and J.F.W.; visualization J.R.-F. and J.F.W.; supervision, J.R.-F. and J.F.W.; project administration J.R.-F.; funding acquisition J.R.-F. and J.F.W. All authors have read and agreed to the published version of the manuscript.

Funding: This research received no external funding; internal faculty development funds were used.

Acknowledgments: We would like to acknowledge the support given by fellow faculty in allowing us their class time to conduct the experiment and for feedback on draft of the manuscript. Further, we would like to thank anonymous referees and the editor for their feedback and insightful comments to greatly improve the paper. Publication of this article in an open-access journal was funded by the Portland State University Library's Open Access Fund.

Conflicts of Interest: The authors declare no conflict of interest. 


\section{Appendix A}

Table A1. A: Demographic information per treatment.

\begin{tabular}{ccccccc}
\hline \multirow{3}{*}{ Gender } & & Five-I & Five-NI & Seven-NI & Seven-I & Total \\
& Male & 16 & 14 & 23 & 20 & 73 \\
& Female & 18 & 19 & 11 & 8 & 56 \\
\multirow{5}{*}{ Rajor } & Other & 0 & 1 & 0 & 0 & 1 \\
& Econ/Business & 29 & 20 & 16 & 12 & 77 \\
& STEM & 1 & 4 & 7 & 10 & 22 \\
& Other & 4 & 10 & 10 & 5 & 29 \\
& White & 13 & 15 & 18 & 17 & 63 \\
& African & 0 & 0 & 1 & 2 & 3 \\
& American & 5 & 8 & 3 & 1 & 17 \\
& Latino/Hispanic & 5 & 5 & 4 & 3 & 21 \\
& Asian & 9 & 5 & 5 & 5 & 19 \\
\hline
\end{tabular}

\section{References}

1. Read, D.; Loewenstein, G.; Rabin, M. Choice Bracketing. J. Risk Uncertain. 1999, 19, 171-197. [CrossRef]

2. Macera, R.; te Velde, V.L. On the Power of Surprising Versus Anticipated Gifts in the Workplace. Work. Pap. 2018. Available online: http://www.rosariomacera.cl/files/pdf_00e66_surprising-gifts.pdf (accessed on 7 November 2020).

3. Fehr, E.; Goette, L.; Zehnder, C. A Behavioral Account of the Labor Market: The Role of Fairness Concerns. Annu. Rev. Econ. 2009, 1, 355-384. [CrossRef]

4. Miner, B.J. Equity Theory: J. Stacy Adams. In Organizational Behavior 1: Essential Theories of Motivation and Leadership, 1st ed.; M.E. Sharpe: New York, NY, USA, 2005; Chapter 9; pp. 134-158.

5. Andrews, I.R. Wage Inequity and Job Performance: An Experimental Study. J. Appl. Psychol. 1967, 51, 39-45. [CrossRef] [PubMed]

6. Viglia, G.; Abrate, G. How Social Comparison Influences Reference Price Formulation in a Service Context. J. Econ. Psychol. 2014, 45, 168-180. [CrossRef]

7. Sliwka, D.; Werner, P. Wage Increases and the Dynamics of Reciprocity. J. Labor Econ. 2017, 35, $299-344$. [CrossRef]

8. Charness, G.; Kuhn, P. Does Pay Inequality Affect Worker Effort? Experimental Evidence. J. Labor Econ. 2007, 25, 693-723. [CrossRef]

9. Hennig-Schmidt, H.; Sadrieh, A.; Rockenback, B. In Search of Workers' Real Effort Reciprocity-A Field and a Laboratory Experiment. J. Eur. Econ. Assoc. 2010, 8, 817-837.

10. Bartling, B.; von Siemens, F.A. Wage Inequality and Team Production: An Experimental Analysis. J. Econ. Psychol. 2011, 32, 1-16. [CrossRef]

11. Sseruyange, J.; Bulte, E. Wage Differentials and Workers' Effort: Experimental Evidence from Uganda. Oxf. Bull. Econ. Stat. 2020, 82, 647-668. [CrossRef]

12. Abeler, J.; Falk, A.; Goette, L.; Huffman, D. Reference Points and Effort Provision. Am. Econ. Rev. 2011, 101, 470-492. [CrossRef]

13. Ericson, K.M.; Fuster, A. Expectations as Endowments: Evidence on Reference-Dependent Preferences from Exchange and Valuation Experiments. Q. J. Econ. 2011, 126, 1879-1907. [CrossRef]

14. Dickson, A.; Fongoni, M. Asymmetric Reference-Dependent Reciprocity, Downward Wage Rigidity, and the Employment Contract. J. Econ. Behav. Organ. 2019, 163, 409-429. [CrossRef]

15. Kahneman, D.; Tversky, A. Prospect Theory: An Analysis of Decision Under Risk. Econometrica 1979, 47, 263-292. [CrossRef]

16. Tversky, A.; Kahneman, D. Loss Aversion in Riskless Choice: A Reference-Dependent Model. Q. J. Econ. 1991, 106, 1039-1061. [CrossRef]

17. Gilchrist, D.S.; Luca, M.; Malhotra, D. When 3 + $1>4$ : Gift Structure and Reciprocity in the Field. Manage. Sci. 2016, 62, 2639-2650. [CrossRef] 
18. Cohn, A.; Fehr, E.; Herrmann, B.; Schneider, F. Social Comparison and Effort Provision: Evidence from a Field Experiment. J. Eur. Econ. Assoc. 2014, 12, 877-898. [CrossRef]

19. Abeler, J.; Altmann, S.; Goerg, S.J.; Kube, S.; Wibral, M. Equity and Efficiency in Multi-Worker Firms: Insights from Experimental Economics. Anal. Krit. 2011, 33, 325-348. [CrossRef]

20. Pfeffer, J.; Langton, N. The Effect of Wage Dispersion on Satisfaction, Productivity, and Working Collaboratively: Evidence from College and University Faculty. Adm. Sci. Q. 1993, 38, 382-407. [CrossRef]

21. Kube, S.; Maréchal, M.; Puppe, C. Do Wage Cuts Damage Work Morale? Evidence from a Natural Field Experiment. J. Eur. Econ. Assoc. 2013, 11, 853-870. [CrossRef]

22. Clark, A.E.; Masclet, D.; Villeval, M.C. Effort and Comparison Income: Experimental and Survey. ILR Rev. 2010, 63, 407-426. [CrossRef]

23. Skott, P. Fairness as a Source of Hysteresis in Employment and Relative Wages. J. Econ. Behav. Organ. 2005, 57, 305-331. [CrossRef]

24. Akerlof, G.A.; Yellen, J.L. The Fair Wage-Effort Hypothesis and Unemployment. Q. J. Econ. 1990, 105, $225-283$. [CrossRef]

25. Abeler, J.; Altmann, S.; Kube, S.; Wibral, M. Gift Exchange and Workers' Fairness Concerns: When Equality is Unfair. J. Eur. Econ. Assoc. 2010, 8, 1299-1324. [CrossRef]

26. Farber, H.S. Is Tomorrow Another Day? The Labor Supply of New York City Cabdrivers. J. Polit. Econ. 2005, 113, 46-82. [CrossRef]

27. Kőszegi, B.; Rabin, M. A Model of Reference-Dependent Preferences. Q. J. Econ. 2006, 121, 1133-1165.

28. Crawford, V.P.; Meng, J. New York City Cab Drivers' Labor Supply Revisited: Reference-Dependent Preferences with Rational-Expectations Targets for Hours and Income. Am. Econ. Rev. 2011, 101, 1912-1932. [CrossRef]

29. Chang, T.; Gross, T. How Many Pears Would a Pear Packer Pack if a Pear Packer Could Pack Pears at Quasi-Exogenously Varying Piece Rates? J. Econ. Behav. Organ. 2014, 99, 1-17. [CrossRef]

Publisher's Note: MDPI stays neutral with regard to jurisdictional claims in published maps and institutional affiliations.

(C) 2020 by the authors. Licensee MDPI, Basel, Switzerland. This article is an open access article distributed under the terms and conditions of the Creative Commons Attribution (CC BY) license (http://creativecommons.org/licenses/by/4.0/). 